\title{
Virtual surgical planning and 3D printing in repeat calvarial vault reconstruction for craniosynostosis: technical note
}

\author{
Melissa LoPresti, MD,, ${ }^{1,3}$ Bradley Daniels, BS, 1,3 Edward P. Buchanan, MD, ${ }^{2,4}$ Laura Monson, MD, ${ }^{2,4}$ \\ and Sandi Lam, MD1,3
}

Departments of ${ }^{1}$ Neurosurgery and ${ }^{2}$ Plastic Surgery, Baylor College of Medicine; and Divisions of ${ }^{3}$ Pediatric Neurosurgery and ${ }^{4}$ Pediatric Plastic Surgery, Texas Children's Hospital, Houston, Texas

\begin{abstract}
Repeat surgery for restenosis after initial nonsyndromic craniosynostosis intervention is sometimes needed. Calvarial vault reconstruction through a healed surgical bed adds a level of intraoperative complexity and may benefit from preoperative and intraoperative definitions of biometric and aesthetic norms. Computer-assisted design and manufacturing using 3D imaging allows the precise formulation of operative plans in anticipation of surgical intervention. 3D printing turns virtual plans into anatomical replicas, templates, or customized implants by using a variety of materials. The authors present a technical note illustrating the use of this technology: a repeat calvarial vault reconstruction that was planned and executed using computer-assisted design and 3D printed intraoperative guides.
\end{abstract}

https://thejns.org/doi/abs/10.3171/2016.10.PEDS16301

KEY WORDS craniosynostosis; computer-assisted design; computer-assisted manufacturing; virtual surgical planning; 3D printing; craniofacial; surgical technique

$\mathrm{C}$ RANIOSYNOSTOSIS has an estimated incidence of 1 in 2500 births. ${ }^{22}$ The sagittal suture is the most commonly involved in single-suture synostosis. ${ }^{6,22}$ Restenosis after initial surgery for sagittal synostosis has been reported to range from $2 \%$ to $16 \%$ in case series. ${ }^{1,4,14,27}$ Reoperation in the setting of restenosis is more challenging than first-time surgery; ${ }^{10,13,19,29}$ it is often complicated by delayed intracranial hypertension and typically requires calvarial vault reconstruction (CVR) through the healed surgical bed to cut the skull, realign bone segments, and reconstruct the calvaria with appropriate expanded dimensions.

Computer-assisted design and manufacturing (CAD/ CAM) is a technique that uses $3 \mathrm{D}$ imaging to render a virtual patient-specific anatomical model that can be used to plan and execute operative maneuvers or customize devices and implants. This allows the precise formulation of operative plans in anticipation of surgical intervention. ${ }^{11}$ With the advent of additive manufacturing in the form of $3 \mathrm{D}$ printing, these virtual plans are materialized into anatomical replicas, cutting guides, or customized splints, prostheses, and implants using a variety of materials. ${ }^{21}$ The use of CAD/CAM for preoperative planning and intraoperative guidance has been reported in orthopedic, ${ }^{2,9,18,30}$ maxillofacial, ${ }^{7,15,26}$ plastic ${ }^{8,11}$ craniocervical spine, ${ }^{20}$ and neurovascular surgery, ${ }^{28}$ among others. Described benefits include decreased operative times, ${ }^{11}$ increased potential for reproducible surgical outcomes that are accurate to intended results, ${ }^{11}$ enhanced patient understanding of surgical pathology and treatment plan, ${ }^{16}$ facilitated learning for surgical residents ${ }^{24}$ and streamlined surgical instrument requirements. ${ }^{18}$

The use of $\mathrm{CAD} / \mathrm{CAM}$ for the cranial reconstruction in children with craniosynostosis has been reported in small numbers, mostly in the plastic surgery community. 3,12,16,17,24,26 This technology allows for patient-specific reconstructions referencing standardized metrics, ${ }^{25}$ aiming for efficiency of execution and reproducibility of surgical outcomes. ${ }^{26}$ Despite its potential benefits, this modality has received less attention by the neurosurgical commu-

ABBREVIATIONS CAD/CAM = computer-assisted design and manufacturing; $C V R=$ calvarial vault reconstruction; $V S P=$ virtual surgical planning . SUBMITTED May 26, 2016. ACCEPTED October 13, 2016.

INCLUDE WHEN CITING Published online February 3, 2017; DOI: 10.3171/2016.10.PEDS16301. 
nity. Here, we present a technical note for discussion in the pediatric neurosurgery community. This is a case of a 15-month-old girl with restenosis of the sagittal suture requiring repeat surgery planned and executed using CAD and $3 \mathrm{D}$ printed intraoperative cutting guides, and it illustrates the use of this new technology.

\section{Case Description}

This 15-month-old girl was born at 39 weeks' gestation without complication. She initially presented developmentally on track at 2 months of age with scaphocephaly (head circumference $91 \%$ percentile; cephalic ratio 0.776 ) and a palpable sagittal ridge, with no signs of elevated intracranial pressure. 3D CT scanning of the head confirmed a diagnosis of single-suture sagittal synostosis. The patient underwent an uneventful endoscopic sagittal synostectomy (4 cm in width) with bilateral wedge-shaped barrel stave osteotomies paired behind the coronal sutures and paired anterior to the lambdoid sutures. Her postoperative course included a custom helmet orthotic as an adjunct to cranial reshaping. Her cephalic ratio improved to 0.822 , which was sustained for the next 9 months.

At 12 months postoperatively, the patient was noted to exhibit visible and palpable bony overgrowth along the synostectomy defect, recapitulation of biparietal narrowing, and frontal bossing, with a notable decrease in her head circumference percentile. Her development was age appropriate, and she had no evidence of elevated intracranial pressure on neurological and ophthalmological examinations. Repeat 3D CT revealed restenosis of the sagittal suture and scaphocephaly, and cranial vault remodeling was recommended to expand the intracranial volume. Due to our center's experience with and accessibility to virtual surgical planning (VSP) and 3-dimensionally printed aides, these were used for the preoperative planning and intraoperative assistance of her calvarial reconstruction.

The 3D CT was used to plan osteotomies with VSP reconstruction (3D Systems Healthcare) (Fig. 1 upper). These planned cuts were virtually manipulated by superior and lateral expansion of bone segments flanking the center cut bone strip to match the dimensions of a normative 2-year-old female cranium (Fig. 1 lower). Using this schematic, a model of the patient's skull was produced with planned osteotomy overlay. This was then used to render a sterilized cutting guide and normative 2-year-old female cranial template with outlines for the planned expansion. The model, cutting guide, and template were created using additive manufacturing (3D printing). Intraoperatively, the sterile manufactured cutting guide was used to mark the location of planned osteotomies on the skull (Fig. 2). Osteotomies were performed, positioned within the expanded outlines on the normative cranial template, and attached
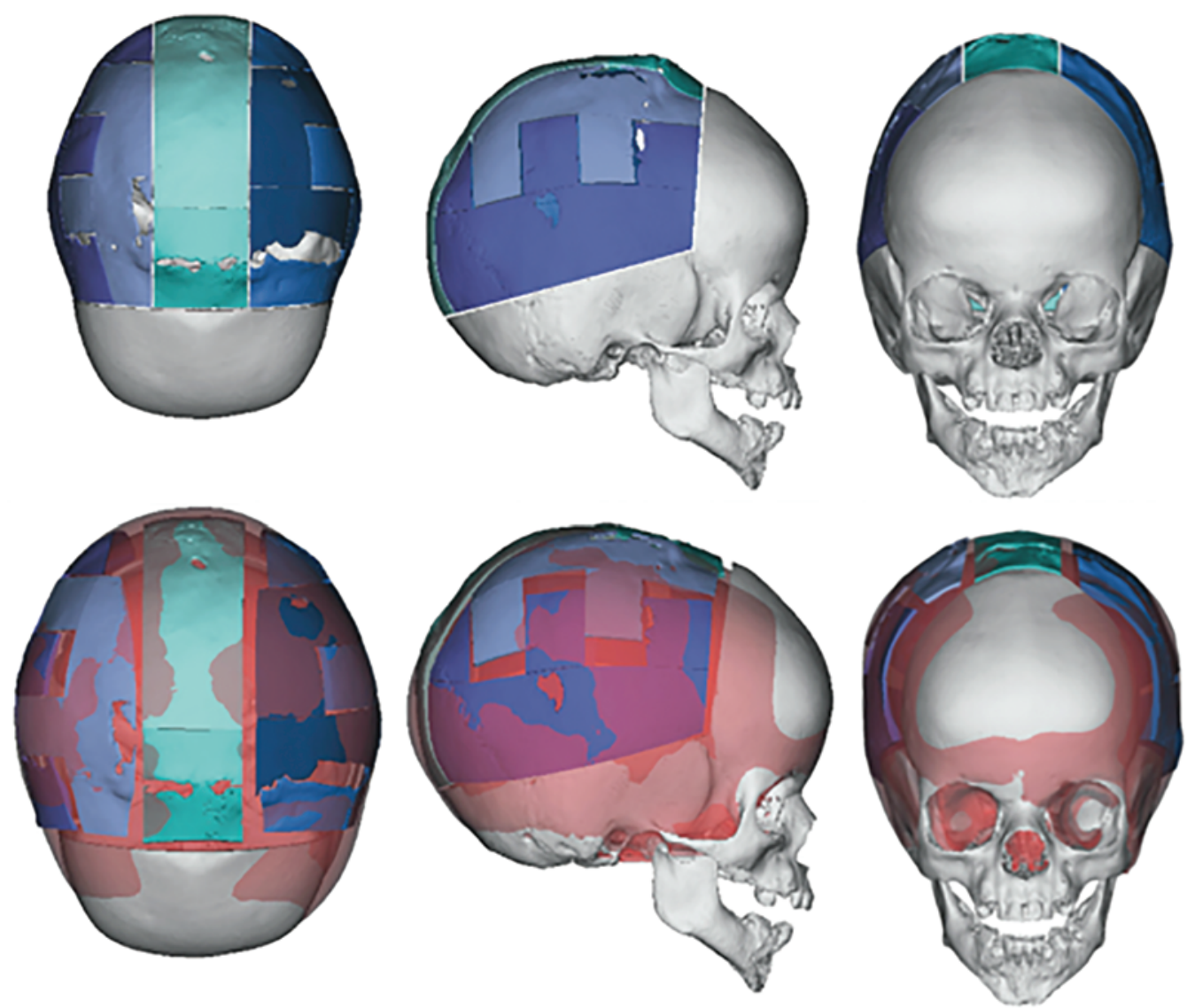

FIG. 1. Preoperative VSP. Upper: 3D head CT scans with virtually planned osteotomies. Lower: Planned expansion to the dimensions of a normative 2-year-old female cranium (superimposed in red). Note lateral (left), where anterior is facing down, and superior (center) distractions with overall outward expansion (right). Figure is available in color online only. 

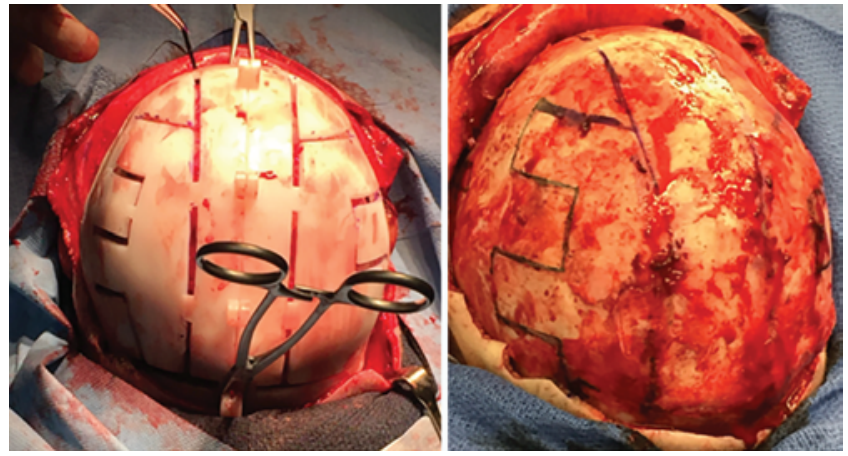

FIG. 2. Use of a sterile cutting guide to mark the location of preoperatively planned osteotomies (patient in prone position). Figure is available in color online only.

using resorbable plates and screws (Fig. 3). The expanded top of the calvaria was placed and secured to the native bone (Fig. 4). Operative blood loss was an estimated 100 $\mathrm{ml}$, and anesthetic duration was 130 minutes. A subgaleal Jackson-Pratt drain was used in the perioperative period for 2 days. Recovery was uneventful, and the patient was discharged to home on postoperative Day 3.

\section{Discussion}

Preoperative VSP and 3D printed intraoperative aides are becoming increasingly useful for the surgical management of conditions in a variety of fields. Table 1 provides a summary of references cited for context. The use of VSP for CVR in patients with craniosynostosis was aided by the generation of normalized cranial templates by Saber and colleagues in 2012. This group rendered composite models representing age- and sex-matched averages for the pediatric calvaria based on 103 samples. ${ }^{23}$ Seruya et al. then described use of these data for CVR using CAD/ CAM in 4 patients with single and multisutural craniosynostosis. They recognized potentials for efficient surgeries with displacement of time-consuming osteotomy planning to the preoperative setting, the development of practiced plans derived from multiple trial-and-error schematizations, and outcomes that precisely match preoperatively intended results. ${ }^{24}$ Other groups have described better establishment of parental expectations through the provision of a tactile aide that models expected results, ${ }^{16}$ as well as improved safety profiles due to preoperatively navigated cuts. ${ }^{5}$ This technology has also been proposed to advance the field with models that enhance trainee education and provide a medium for surgical innovation..$^{24}$

While the benefits of CAD/CAM for CVR seem promising, there is much to be explored. The most frequently cited barriers to this technique include potentially prohibitive cost, accessibility, and radiation exposure. ${ }^{5,16,23}$ The financial burden of CAD/CAM for CVR is not well studied, though it has been cited as a potential barrier to utility. ${ }^{5,16}$ However, cost-effectiveness analyses undertaken for CAD/CAM-facilitated maxillofacial and plastic surgeries have demonstrated reductions in both time and material cost when compared with conventional techniques. ${ }^{8,31}$ It is nevertheless important for the surgeon to review the cost associated with using CAD/CAM for CVR at their
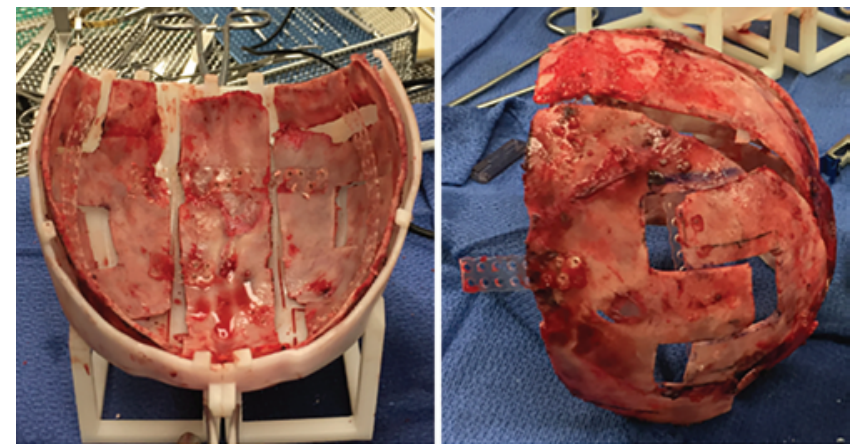

FIG. 3. Left: Alignment of cut bone segments within the expansion guidelines of the normative cranial mold and fastening with absorbable plates and screws. Right: Final expanded calvarial construct (middle and posterior calvarial vault). Figure is available in color online only.

institution as well as patient insurance to assess levels of coverage. ${ }^{24}$ The number of centers offering CVRs using $\mathrm{CAD} / \mathrm{CAM}$ is small. Its implementation may therefore be limited to patients residing near major cities where there is access to centers adopting such technology. While some authors have cited increased radiation exposure in the preoperative period as a disadvantage to this technique,, 523 $\mathrm{CAD} / \mathrm{CAM}$ planning in our case was based on imaging already obtained for clinical workup, which is standard for conventionally planned reconstructions. No additional CT scans were required.

Our case highlights the benefits of using CAD/CAM for repeat CVR to achieve ease and safety of workflow, a well-educated patient family, and precision in surgical outcomes. In our patient a normal calvarial volume

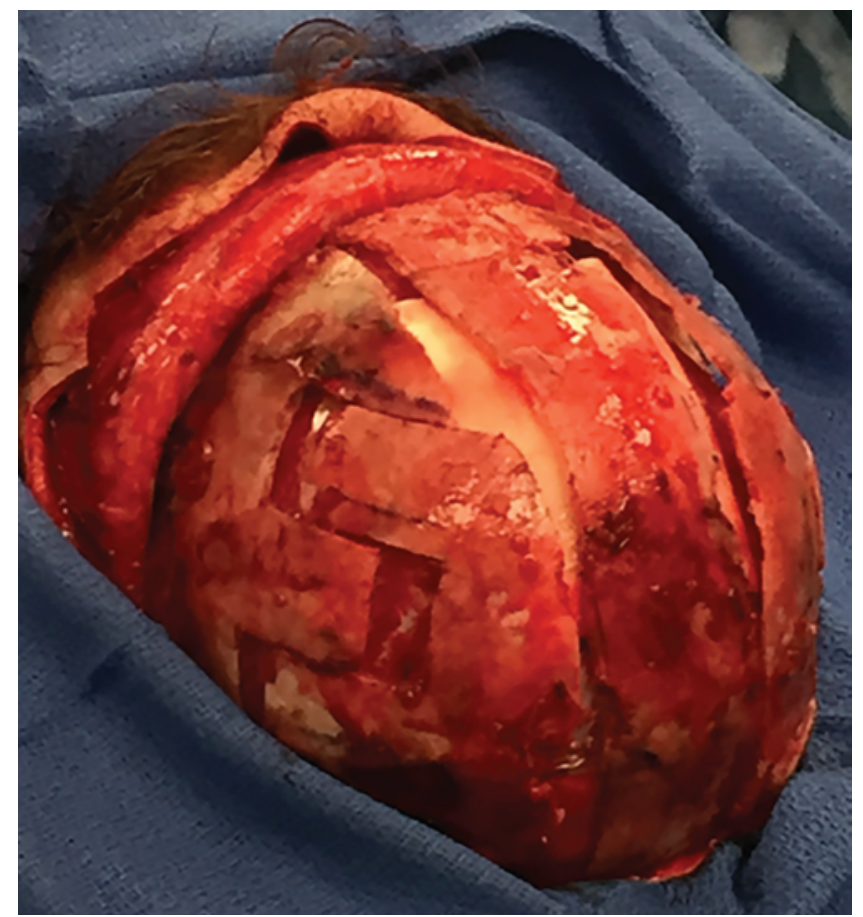

FIG. 4. Placement of expanded calvaria onto the skull with lateral attachments to native bone (patient in prone position). Figure is available in color online only. 
TABLE 1. Summary of references cited

\begin{tabular}{|c|c|}
\hline $\begin{array}{l}\text { Surgical Field/ } \\
\text { Authors \& Year }\end{array}$ & $\begin{array}{l}\text { Described } \\
\text { Uses }\end{array}$ \\
\hline \multicolumn{2}{|l|}{ Orthopedic surgery } \\
\hline Goh et al., 1990 & $\begin{array}{l}\text { Models, cutting guides, \& customized } \\
\text { orthopedic implants }\end{array}$ \\
\hline Ast et al., 2012 & Cutting guides for total knee arthroplasty \\
\hline Nam et al., 2016 & Cutting guides for total knee arthroplasty \\
\hline \multicolumn{2}{|l|}{ Plastic surgery } \\
\hline Mommaerts et al., 2001 & Cutting guides for CVR \\
\hline Burge et al., 2011 & $\begin{array}{l}\text { Cutting guides for CVR/frontoorbital } \\
\text { advancement }\end{array}$ \\
\hline Dérand et al., 2012 & Implants for mandibular reconstruction \\
\hline Levine et al., 2012 & $\begin{array}{l}\text { Models, cutting guides, \& implants for } \\
\text { facial reconstruction }\end{array}$ \\
\hline Seruya et al., 2013 & Cutting guides for CVR \\
\hline Parthasarathy, 2014 & $\begin{array}{l}\text { Cranioplasty implants, mandibular \& } \\
\text { facial reconstruction }\end{array}$ \\
\hline Chim et al., 2014 & $\begin{array}{l}\text { Cutting guides for CVR \& distraction } \\
\text { osteogenesis }\end{array}$ \\
\hline Mardini et al., 2014 & Cutting guides for CVR \\
\hline Khechoyan et al., 2014 & Cutting guides for CVR \\
\hline Steinbacher, 2015 & $\begin{array}{l}\text { Cranioplasty implants, cutting guides for } \\
\text { frontoorbital \& midfacial advancement, } \\
\text { \& mandibular reconstruction }\end{array}$ \\
\hline Kamali et al., 2016 & $\begin{array}{l}\text { Mandibular reconstruction, patient-specif- } \\
\text { ic prostheses, \& soft-tissue scaffolds }\end{array}$ \\
\hline \multicolumn{2}{|l|}{ Neurological surgery } \\
\hline Soleman et al., 2015 & $\begin{array}{l}\text { Cutting guide for CVR/frontoorbital } \\
\text { advancement }\end{array}$ \\
\hline Weinstock et al., 2015 & $\begin{array}{l}\text { Model of vascular malformations for } \\
\text { surgical planning }\end{array}$ \\
\hline Pacione et al., 2016 & $\begin{array}{l}\text { Model of craniocervical junction for surgi- } \\
\text { cal planning of correction of complex } \\
\text { deformity }\end{array}$ \\
\hline Present case & Cutting guide for repeat CVR \\
\hline
\end{tabular}

and shape were achieved after she underwent a wellplanned and smoothly executed cranial reconstruction. We noted less intraoperative blood loss in this case than in conventionally performed repeat CVRs. The median estimated blood volume loss for standard repeat CVRs is approximately $109 \%,{ }^{10}$ which is significantly greater than the that seen in our case, calculated to be $26.5 \%$. With CAD/CAM, this repeat surgery made efficient use of intraoperative time; the process was facilitated by preconstructed templates for osteotomy and bone rearrangement. Of course, these maneuvers did not replace the surgical team's intraoperative judgment, and each step in the patient's repeat reconstruction was double-checked and cross-referenced with the intraoperative experience of the surgeons performing the procedure. Conclusions about outcomes cannot be drawn with this illustrative case. Directions for future research call for prospective study of a larger number of patients.

\section{Conclusions}

Computer-aided design and modeling with 3D printed intraoperative aids for repeat cranial vault surgery represents a relatively novel incorporation of technology in pediatric neurosurgery. The risk/benefit profile of this new advancement is promising, and it is potentially an option for facilitating the course of children undergoing repeat CVR. This modality is logically applicable to reconstructive surgeries by pediatric neurosurgeons and plastic surgeons and may find utility in a variety of other procedures.

\section{References}

1. Adamo MA, Pollack IF: A single-center experience with symptomatic postoperative calvarial growth restriction after extended strip craniectomy for sagittal craniosynostosis. J Neurosurg Pediatr 5:131-135, 2010

2. Ast MP, Nam D, Haas SB: Patient-specific instrumentation for total knee arthroplasty: a review. Orthop Clin North Am 43:e17-e22, 2012

3. Burge J, Saber NR, Looi T, French B, Usmani Z, Anooshiravani $\mathrm{N}$, et al: Application of CAD/CAM prefabricated age-matched templates in cranio-orbital remodeling in craniosynostosis. J Craniofac Surg 22:1810-1813, 2011

4. Cetas JS, Nasseri M, Saedi T, Kuang AA, Selden NR: Delayed intracranial hypertension after cranial vault remodeling for nonsyndromic single-suture synostosis. J Neurosurg Pediatr 11:661-666, 2013

5. Chim H, Wetjen N, Mardini S: Virtual surgical planning in craniofacial surgery. Semin Plast Surg 28:150-158, 2014

6. Delashaw JB, Persing JA, Broaddus WC, Jane JA: Cranial vault growth in craniosynostosis. J Neurosurg 70:159-165, 1989

7. Dérand P, Rännar LE, Hirsch JM: Imaging, virtual planning, design, and production of patient-specific implants and clinical validation in craniomaxillofacial surgery. Craniomaxillofac Trauma Reconstr 5:137-144, 2012

8. Gerstle TL, Ibrahim AMS, Kim PS, Lee BT, Lin SJ: A plastic surgery application in evolution: three-dimensional printing. Plast Reconstr Surg 133:446-451, 2014

9. Goh JC, Ho NC, Bose K: Principles and applications of computer-aided design and computer-aided manufacturing (CAD/CAM) technology in orthopaedics. Ann Acad Med Singapore 19:706-713, 1990

10. Howe PW, Cooper MG: Blood loss and replacement for paediatric cranioplasty in Australia-a prospective national audit. Anaesth Intensive Care 40:107-113, 2012

11. Kamali P, Dean D, Skoracki R, Koolen PGL, Paul MA, Ibrahim AMS, et al: The current role of three-dimensional printing in plastic surgery. Plast Reconstr Surg 137:1045-1055, 2016

12. Khechoyan DY, Saber NR, Burge J, Fattah A, Drake J, Forrest CR, et al: Surgical outcomes in craniosynostosis reconstruction: the use of prefabricated templates in cranial vault remodelling. J Plast Reconstr Aesthet Surg 67:9-16, 2014

13. Kuang A, Selden NR: Secondary cranial vault remodeling for restenosis after primary sagittal synostosis repair. Pediatr Neurosurg 50:104-108, 2015

14. Lam S, Wagner KM, Middlebrook E, Luerssen TG: Delayed intracranial hypertension after surgery for nonsyndromic craniosynostosis. Surg Neurol Int 6:187-190, 2015

15. Levine JP, Patel A, Saadeh PB, Hirsch DL: Computer-aided design and manufacturing in craniomaxillofacial surgery: the new state of the art. J Craniofac Surg 23:288-293, 2012

16. Mardini S, Alsubaie S, Cayci C, Chim H, Wetjen N: Threedimensional preoperative virtual planning and template use for surgical correction of craniosynostosis. J Plast Reconstr Aesthet Surg 67:336-343, 2014 
17. Mommaerts MY, Jans G, Vander Sloten J, Staels PFJ, Van der Perre G, Gobin R: On the assets of CAD planning for craniosynostosis surgery. J Craniofac Surg 12:547-554, 2001

18. Nam D, Nunley RM, Berend KR, Lombardi AV, Barrack RL: The impact of custom cutting guides on patient satisfaction and residual symptoms following total knee arthroplasty. Knee 23:144-148, 2016

19. Norwood CW, Alexander E Jr, Davis CH Jr, Kelly DL Jr: Recurrent and multiple suture closures after craniectomy for craniosynostosis. J Neurosurg 41:715-719, 1974

20. Pacione D, Tanweer O, Berman P, Harter DH: The utility of a multimaterial 3D printed model for surgical planning of complex deformity of the skull base and craniovertebral junction. J Neurosurg Pediatr 125:1194-1197, 2016

21. Parthasarathy J: 3D modeling, custom implants and its future perspectives in craniofacial surgery. Ann Maxillofac Surg 4:9-18, 2014

22. Persing JA: MOC-PS(SM) CME article: management considerations in the treatment of craniosynostosis. Plast Reconstr Surg 121 (4 Suppl): 1-11, 2008

23. Saber NR, Phillips J, Looi T, Usmani Z, Burge J, Drake J, et al: Generation of normative pediatric skull models for use in cranial vault remodeling procedures. Childs Nerv Syst 28:405-410, 2012

24. Seruya M, Borsuk DE, Khalifian S, Carson BS, Dalesio NM, Dorafshar AH: Computer-aided design and manufacturing in craniosynostosis surgery. J Craniofac Surg 24:1100-1105, 2013

25. Soleman J, Thieringer F, Beinemann J, Kunz C, Guzman R: Computer-assisted virtual planning and surgical template fabrication for frontoorbital advancement. Neurosurg Focus 38(5):E5, 2015

26. Steinbacher DM: Three-dimensional analysis and surgical planning in craniomaxillofacial surgery. J Oral Maxillofac Surg 73 (12 Suppl):S40-S56, 2015

27. Thomas GPL, Johnson D, Byren JC, Judge AD, Jayamohan J, Magdum SA, et al: The incidence of raised intracranial pressure in nonsyndromic sagittal craniosynostosis following primary surgery. J Neurosurg Pediatr 15:350-360, 2015
28. Weinstock P, Prabhu SP, Flynn K, Orbach DB, Smith E: Optimizing cerebrovascular surgical and endovascular procedures in children via personalized 3D printing. J Neurosurg Pediatr 16:1-6, 2015

29. Williams JK, Cohen SR, Burstein FD, Hudgins R, Boydston W, Simms C: A longitudinal, statistical study of reoperation rates in craniosynostosis. Plast Reconstr Surg 100:305-310, 1997

30. Wong KC, Kumta SM, Leung KS, Ng KW, Ng EWK, Lee $\mathrm{KS}$ : Integration of CAD/CAM planning into computer assisted orthopaedic surgery. Comput Aided Surg 15:65-74, 2010

31. Xia JJ, Phillips CV, Gateno J, Teichgraeber JF, Christensen AM, Gliddon MJ, et al: Cost-effectiveness analysis for computer-aided surgical simulation in complex cranio-maxillofacial surgery. J Oral Maxillofac Surg 64:1780-1784, 2006

\section{Disclosures}

The authors report no conflict of interest concerning the materials or methods used in this study or the findings specified in this paper.

\section{Author Contributions}

Conception and design: Lam, Buchanan, Monson. Acquisition of data: Lam, LoPresti, Daniels, Buchanan. Analysis and interpretation of data: Lam, LoPresti. Drafting the article: LoPresti, Daniels. Critically revising the article: all authors. Reviewed submitted version of manuscript: Lam, LoPresti, Buchanan, Monson. Approved the final version of the manuscript on behalf of all authors: Lam. Administrative/technical/material support: Lam. Study supervision: Lam.

\section{Correspondence}

Sandi Lam, Department of Neurosurgery, Texas Children's Hospital, 6701 Fannin St., CCC 1230.01, Houston, TX 77030. email: sklam@texaschildrens.org. 